\title{
Approaches to the Management of Agents Used for the Treatment of Multiple Sclerosis: Consensus Statements from a Panel of U.S. Managed Care Pharmacists and Physicians
}

\author{
Ross M. Miller, MD, MPH; Laura E. Happe, PharmD, MPH; \\ Kellie L. Meyer, PharmD, MPH; and Rachel J. Spear, PharmD
}

\begin{abstract}
BACKGROUND: Multiple sclerosis (MS) is a chronic, disabling, and costly disease with several treatment options available; however, there is variability in evidence-based clinical guidelines. Therefore, payers are at a disadvantage when making management decisions without the benefit of definitive guidance from treatment guidelines.

OBJECTIVE: To outline approaches for the management of agents used to treat MS, as determined from a group of U.S. managed care pharmacists and physicians.

METHODS: A modified Delphi process was used to develop consensus statements regarding MS management approaches. The panel was composed of experts in managed care and included 8 pharmacy directors and 6 medical directors presently or previously involved in formulary decision making from 12 health plans, 1 specialty pharmacy, and 1 consulting company. These decision makers, who have experience designing health care benefits that include MS treatments, provided anonymous feedback through 2 rounds of web-based surveys and participated in 1 live panel meeting held in December 2010. Consensus was defined as a mean response of at least 3.3 or $100 \%$ of responses either "agree" or "strongly agree" (i.e., no panelist answered "disagree" or "strongly disagree") on a 4 -item Likert scale ( 1 = strongly disagree, $2=$ disagree, $3=$ agree, $4=$ strongly agree).

RESULTS: After 3 phases, these managed care representatives reached consensus on 25 statements for management of patients with MS. Consistent with managed care principles, this group of managed care experts found that health plans should consider efficacy, effectiveness, and safety, as well as patient preference, when evaluating MS therapies for formulary placement. Cost and contracting should be considered if efficacy and safety are judged to be comparable between agents.
\end{abstract}

CONCLUSION: The consensus statements developed by a panel of managed care representatives provide some insight into decision making in formulary and utilization management of MS therapies.

J Manag Care Pharm. 2012;18(1):54-62

Copyright @2012, Academy of Managed Care Pharmacy. All rights reserved.

\section{What is already known about this subject}

- There are several clinical treatment guidelines for multiple sclerosis (MS) in the United States and the United Kingdom, but the principal guideline from the American Academy of Neurology (AAN) in the United States is outdated (2002) and much less comprehensive than the National Institute of Clinical Excellence (NICE) guideline that is also dated (2003).

- There is variability among the clinical treatment guidelines regarding the use of pharmacologic agents for the treatment of MS, and payers lack updated clinical guidance on which to base insurance benefit design decisions.

\section{What this study adds}

- Consensus, defined as a mean score of at least 3.3 on a 4-point Likert scale or no panelist answering "disagree" or "strongly disagree" on the same 4-item Likert scale, was attained for 25 statements presented to a panel of managed care pharmacists and physicians over 2 anonymous web-based surveys followed by a live meeting.

$\mathrm{M}$ ultiple sclerosis (MS) is a chronic, disabling, costly disease with several treatment options available. While treatment guidelines exist for MS, there is wide variation in the topics discussed among the 3 primary sources, including the American Academy of Neurology (AAN), European Federation of Neurological Societies (EFNS), and National Institute for Health and Clinical Excellence (NICE). ${ }^{1}$ For example, the NICE guidelines are used by the National Health Service to determine drug coverage in the United Kingdom and therefore include data on health economics and cost-effectiveness analyses. ${ }^{1}$ Also, the NICE guidelines include guidance for consumers and recommendations from patientreported outcomes, while the AAN and EFNS guidelines use only evidence derived from physician-reported outcomes in describing MS diagnosis and treatment options. ${ }^{1}$ In addition to the wide variation in topics discussed, new agents, such as fingolimod and dalfampridine, have been approved in the past year for the treatment and symptom management of MS and are not addressed in the guidelines. ${ }^{1}$ Therefore, U.S. payers face a challenge when making management decisions without the benefit of guidance from specific treatment guidelines.

Approximately 400,000 persons in the United States have MS, ${ }^{2}$ and the clinical course, severity, disability, and symptoms vary from patient to patient. ${ }^{3}$ Relapsing-remitting MS (RRMS) is the most common type and is characterized by intermittent episodes of neurological deterioration (relapses) with periods of clinical stability occurring between attacks. ${ }^{2,3}$ Eighty-five percent of all patients with MS initially present with clinically isolated syndrome (CIS), defined as a first neurological attack caused by central nervous system (CNS) demyelination. ${ }^{4}$ Most patients (68\%) with CIS later develop clinically definite MS (CDMS), characterized by a second clinical attack or new brain 
magnetic resonance imaging (MRI)-confirmed lesions., ${ }^{5,6}$

MS typically presents in women between the ages of 20 and 40 years, a demographic that is commonly covered by commercial health insurance..$^{7-9}$ Ultimately, patients with MS may progress to full disability, leading to Medicare coverage. The economic impact of MS to the third-party payer is significant. ${ }^{10}$ A retrospective database analysis reported by Asche et al. (2010), which analyzed pharmacy and medical claims for commercial health plans between 2004 and 2006, estimated the mean total direct all-cause cost per patient with MS to be nearly $\$ 19,000$ over a 12 -month period and noted that costs were approximately 4.7 times higher for newly diagnosed MS patients compared with healthy plan members without MS. ${ }^{10}$ Although adjusted to 2010 using the Consumer Price Index, only one-fourth of the average costs were attributed to MS-injectable drugs. This is a limitation of the analysis by Asche et al., since new agents have entered the market since 2006, and the prices of the agents used for the treatment of MS have increased over time. ${ }^{11}$

The objectives of treating MS are to prevent relapses and delay disability progression. ${ }^{12}$ A platform therapy has been defined as an agent that will provide baseline immunomodulatory action and can be administered for an extended period of time..$^{13}$ The platform therapies, including glatiramer acetate (Copaxone) and the interferons (IFNs) IFN beta-la intramuscular (IFN $\beta$-la IM; Avonex), IFN beta-lb subcutaneous (IFN $\beta-1 b$ SC; Betaseron and Extavia), and IFN $\beta$-la SC (Rebif) are indicated for patients with relapsing forms of MS to reduce the frequency of clinical exacerbations. ${ }^{14-18}$ IFN $\beta-1 \mathrm{la}$ IM and IFN $\beta$-la SC are also approved to slow/delay the accumulation of physical disability. In addition, IFN $\beta-1$ Ia IM, IFN $\beta-1 b$ SC, and glatiramer acetate are approved for patients who have experienced a first clinical episode (i.e., CIS). These platform therapies are commonly used when patients initially show signs of relapsing MS; however, when to initiate treatment and which therapy to use remain controversial. ${ }^{3}$ Natalizumab, an integrin receptor antagonist, is indicated as "monotherapy for patients with relapsing forms" of MS and "is generally recommended for patients who have had an inadequate response to, or are unable to tolerate, an alternate MS therapy"19 (Table 1).

Currently, 2 oral agents are approved by the U.S. Food and Drug Administration (FDA) for use in patients with MS. Fingolimod was approved by the FDA in September 2010 to reduce relapses and delay disability progression in patients with relapsing forms of MS. ${ }^{20}$ Dalfampridine was approved in January 2010 and is the first treatment in the United States to improve walking in patients with MS as demonstrated by an increase in walking speed. ${ }^{21}$ Dalfampridine is not a platform therapy and does not alter the MS disease course. The approved MS indication, dosage, and administration from the prescribing information of the platform therapies and other MS agents, including natalizumab, fingolimod, and dalfampridine, are listed in Table 1.
While the addition of oral disease-modifying agents and agents used to treat the symptoms of MS provides more treatment options, close evaluation of efficacy, safety, and cost associated with all MS therapies is important for patients, clinicians, and payers. Therefore, the purpose of this study was to develop consensus statements outlining approaches for the management of agents used to treat MS, as determined by a group of United States managed care decision makers. The consensus statements resulting from this study are intended to serve as a practical reference tool for health plans, to be used in conjunction with clinical evidence, when designing benefits and coverage policies for MS agents.

\section{Methods}

This study used a Delphi process, which is commonly used to identify evidence that is best determined from group involvement or an expert panel and may be used to develop consensus guidelines. ${ }^{22-24}$ Typically, the Delphi process maintains anonymity among participants to help eliminate potential bias by allowing participants to respond openly. ${ }^{24}$ However, a completely anonymous approach prevents the opportunity for potentially valuable discussion and debate that can facilitate consensus. Therefore, modified Delphi approaches have been developed to incorporate both anonymous responses and face-to-face discussions from experts to finalize consensus. ${ }^{25,26}$ Given the objective of this study, a modified Delphi approach, which included a live meeting, was selected as the methodology.

A Delphi panel requires identification of those who are well informed about the specified field. ${ }^{22,23}$ The current panel consisted of experts in managed care and included 8 pharmacy directors and 6 medical directors from 12 U.S. health plans, 1 specialty pharmacy, and 1 consulting company who were presently or previously involved in the formulary decisionmaking process at their organizations. The panelists represented approximately 110 million covered lives. Specifically, the covered lives represented the following insurance types: 80 million commercial, 14.8 million Medicare, 11.7 million selffunded, and 3.4 million Medicaid. Panelists were not required to be experts in the treatment of MS, but the panel members were provided with background reading material on MS. The panel was chaired by a medical director who was selected by the consulting company Xcenda based on previous Delphi panel experience and work in MS. The chairperson approved all questionnaires and study materials.

The protocol used for this study included 2 rounds of webbased surveys followed by a live consensus meeting that was held on December 11, 2010. The first-round survey consisted of mostly open-ended questions (98\%), which is typical in the Delphi process. ${ }^{23}$ The second-round survey included mostly close-ended questions (98\%). If fewer than 33\% of panelists responded in the same way to an open-ended question, then 


\section{TABLE 1 Drug Therapies for MS Considered by the Consensus Panel}

Drug and Date of FDA

Approval

Interferon $\beta$-lb SC

(Betaseron)

July 1993
FDA-Approved Indication(s)

"Treatment of relapsing forms of MS to reduce the frequency of clinical exacerbations. Patients with MS in whom efficacy has been demonstrated include patients who have experienced a first clinical episode and have MRI features consistent with MS." 15,16

Interferon $\beta$-la IM

(Avonex)

May 1996

"Treatment of patients with relapsing forms of MS to slow the accumulation of physical disability and decrease the frequency of clinical exacerbations. Patients with MS in whom efficacy has been demonstrated include patients who have experienced a first clinical episode and have MRI features consistent with MS. Safety and efficacy in patients with chronic progressive MS have not been established." 17

Glatiramer acetate SC

(Copaxone)

"Reduction of the frequency of relapses in patients with

enced a first clinical episode and have MRI features consistent with MS." 14

Interferon $\beta$-la SC

(Rebif)

March 2002
Dosage and Administration

"The recommended dose is $0.25 \mathrm{mg}$ injected SC every other day. Generally, start at $0.0625 \mathrm{mg}(0.25 \mathrm{~mL}) \mathrm{SC}$ every other day, and increase over a 6 -week period to $0.25 \mathrm{mg}(1 \mathrm{~mL})$ every other day." 15,16

"The recommended dosage is $30 \mathrm{mcg}$ injected IM once a week." 17
December 1996

Relapsing-Remitting MS, including patients who have experi-
"Treatment of patients with relapsing forms of MS to decrease the frequency of clinical exacerbations and delay the accumulation of physical disability. Efficacy in chronic progressive MS has not been established."18
"For SC injection only; recommended dose is $20 \mathrm{mg} /$ day." 14

"Dosages shown to be safe and effective are $22 \mathrm{mcg}$ and 44 mcg injected SC 3 times per week (tiw). IFN $\beta$-la SC should be administered, if possible, at the same time (preferably in the late afternoon or evening) on the same 3 days (e.g., Monday, Wednesday, and Friday) at least 48 hours apart each week. Generally, patients should be started at $20 \%$ of the prescribed dose tiw and increased over a 4 -week period to the targeted dose, either 22 mcg or 44 mcg tiw." 18

"300 mg infused intravenously over approximately 1 hour every 4 weeks. Do not give as an intravenous push or bolus. Natalizumab solution must be administered within 8 hours of preparation. Natalizumab is available only through a special restricted distribution program called the TOUCH Prescribing Program and must be administered only to patients enrolled in this program." 19

The recommended dose is $0.25 \mathrm{mg}$ injected SC every other day. Generally, patients should be started at $0.0625 \mathrm{mg}(0.25 \mathrm{~mL})$ SC every other day, and increased over a 6 -week period to 0.25 $\mathrm{mg}(1 \mathrm{~mL})$ every other day. ${ }^{15}$ has been demonstrated include patients who have experienced a first clinical episode and have MRI features consistent with MS." 15

(Extavia)
August 2009

"Indicated to improve walking in patients with MS. This was

Dalfampridine

(Ampyra)

demonstrated by an increase in walking speed."21

January 2010

Fingolimod

(Gilenya)

September 2010

"Treatment of patients with relapsing forms of MS to reduce the frequency of clinical exacerbations and to delay the accumulation of physical disability." 20
"Maximum recommended dose is $10 \mathrm{mg}$ twice daily (approximately 12 hours apart) with or without food."21

"The recommended dose is $0.5 \mathrm{mg}$ orally once daily, with or without food." 20

FDA =U.S. Food and Drug Administration; IFN = interferon; IM = intramuscular; $m c g=$ microgram; $m g=$ milligram; $m L=$ milliliter; $M R I=m a g n e t i c$ resonance imaging; MS = multiple sclerosis; SC=subcutaneous; tiw = 3 times weekly; TOUCH = Tysabri Outreach: Unified Commitment to Health.

that question was considered unlikely to reach consensus and was discarded. Qualitative responses cited by more than 33\% of panelists were converted to affirmative statements and presented in the next round to try to obtain consensus. The panelists were asked to respond to the affirmative statements using a 4-point Likert scale (4 =Strongly Agree, 3 =Agree, 2 = Disagree, $1=$ Strongly Disagree).

Consensus thresholds were determined for categorical data a priori. The panel defined consensus as a mean score of at least 3.3 or 100\% of responses either "agree" or "strongly agree" (i.e., no panelist answered "disagree" or "strongly disagree") based on the 4-point Likert scale. Closed-ended questions from
Survey 2 that did not reach consensus were presented to the panelists again at the live consensus meeting. Panelists were asked to reconsider their responses in light of the group average, but they were advised that revising their original responses was not mandatory. Audience-response keypads were used at the live consensus meeting, which preserved anonymity of quantitative responses. The live consensus meeting provided the opportunity to gain qualitative context around topics that achieved consensus in Survey 2 and at the live meeting, as well as those that did not. The same panelists were involved in all 3 phases of the Delphi process.

For example, $79 \%, 7 \%$, and $14 \%$ of panelists responded with 
"yes," "no," and "unknown/other," respectively, in response to this open-ended question in Survey 1: "Should all patients with CDMS be treated with a disease-modifying therapy?" Since fewer than 33\% of panelists responded "no" or "unknown/ other," and more than 33\% of panelists responded "yes," the question was converted to an affirmative statement in Survey 2: "All patients with CDMS should be treated with a diseasemodifying therapy." The mean response using the 4-point Likert scale was 3.21; therefore, the question was asked again at the live meeting with a slight variation: "Most patients with CDMS should be treated with a disease-modifying therapy." This statement reached consensus based on the 4-item Likert scale with a mean response of 3.4. Table 2 provides examples of selected statements and scoring results from the 3 phases of the consensus panel.

\section{Results}

The consensus statements (Table 3) are based on the results from the 2 web-based surveys and the live meeting (available from the authors by request). The results presented below are based on both the consensus statements and the discussion that the panelists had during the live meeting.

\section{Management of Platform Therapies}

The panel addressed several topics with respect to formulary management of the platform therapies for MS. First, the panel reached consensus that decisions regarding when a CIS patient should start disease-modifying therapy for MS should be made by the health care provider. Nearly reaching consensus, the panel concluded that if a diagnosis of CIS/CDMS is documented, health plans should not implement restrictions regarding when a patient can be started on a disease-modifying therapy. The panel discussed that a health plan may require documentation of diagnosis, and the panel reached consensus that most patients with CDMS should be treated with a disease-modifying therapy. In the live-meeting discussion, the panel recognized that the IFNs and glatiramer acetate have distinct mechanisms of action, and glatiramer acetate is the only disease-modifying agent that is classified as pregnancy risk category B.

Given the lack of a neurologist-endorsed treatment algorithm prioritizing these 2 classes, and because some patients may not tolerate some therapies, the panel discussed that health plans should provide options to MS patients. The panel reached consensus that the options should include preferred access to platform therapies, including glatiramer acetate and at least one IFN. The panelist discussed that access to IFNs does not need to be limited to just 1 IFN. There are currently 3 high-dose/ high-frequency IFNs available in the United States: 2 IFN $\beta-1 b$ SC products, which are identical in every way except name and manufacturer, and 1 IFN $\beta$-la SC product. IFN $\beta$-la IM is the only low-dose/low-frequency IFN available in the United States. Since there is more than 1 high-dose/high-frequency IFN, the panel discussed management among the high-dose/ high-frequency IFNs. The panel reached consensus that health plans should have 1 preferred high-dose/high-frequency IFN on formulary, but during discussion they did not recommend which of the 3 available agents should be in the preferred position. "Preferred" status indicates that these agents would not have utilization management restrictions, such as step therapy. The panel reached consensus that access to nonpreferred IFNs should be restricted by step therapy or use of a preferred agent first. The panel did not achieve consensus on whether patients should be required to use more than 1 IFN (such as a highdose/high-frequency IFN and a low-dose/low-frequency IFN) prior to trying an agent with another mechanism of action. The panel reached consensus that efficacy, safety, cost, and contracting should be taken into consideration when selecting the preferred high-dose/high-frequency IFN for formulary. The panel did discuss that if efficacy and safety are judged to be comparable among agents, then cost and contracting should be considered as secondary means to formulary assessment.

The panel did not reach consensus on whether health plans should restrict laboratory monitoring or diagnostic imaging for patients on platform therapies. During the discussion, some panelists stated that laboratory monitoring and imaging should be left up to the provider, while others advocated utilization management by the health plan; details of the utilization management criteria were not discussed by the panel. However, the panelists indicated during their discussion that if laboratorymonitoring requirements are included in the prescribing information or the Risk Evaluation and Mitigation Strategies (REMS) program for a product, health plans will have a difficult time restricting access to the laboratory monitoring.

\section{Management of Nonplatform Therapies: Natalizumab, Fingolimod, and Dalfampridine}

Natalizumab increases the risk of progressive multifocal leukencephalopathy (PML) and is available only through a special, restricted distribution program called the TOUCH (Tysabri Outreach: Unified Commitment to Health) Prescribing Program. According to the prescribing information, natalizumab is indicated for patients with relapsing forms of MS to delay the accumulation of physical disability and reduce the frequency of clinical exacerbations. ${ }^{19}$ Because natalizumab increases the risk of PML, it is generally recommended for patients who have had an inadequate response to, or are unable to tolerate, an alternate MS therapy. ${ }^{19}$ For appropriate patients, the indication does allow for first-line use of natalizumab. Accordingly, the panel reached consensus that formulary restrictions should be in place to limit natalizumab's use to the FDA-approved indications. In addition, the panel reached 


\section{Approaches to the Management of Agents Used for the Treatment of Multiple Sclerosis: Consensus Statements from a Panel of U.S. Managed Care Pharmacists and Physicians}

\section{TABLE 2 Selected Statements and Scoring from the 3 Phases of the Consensus Panel ${ }^{\mathrm{a}}$}

Survey 1 Results (selected questions)

[Section] Statement

\begin{tabular}{|l|l|l|l} 
& \\
\hline & $P r$
\end{tabular}

[platform therapies]

2.1 How should a health plan manage patient access to platform therapies, if at all?

[platform therapies]

2.6 Should glatiramer acetate be a preferred agent on a health plan's formulary?

[fingolimod]

4.5 Should formulary restrictions be put in place to

limit the use of fingolimod to neurologists?

\begin{tabular}{|l|c}
\multicolumn{1}{|c|}{ Response } & Response \% (n/total) \\
\hline Prior authorization (PA) & $21(3 / 14)$ \\
\hline $\begin{array}{l}\text { Didn't understand what platform thera- } \\
\text { pies meant and didn't provide an answer }\end{array}$ & $21(3 / 14)$ \\
\hline No & $14(2 / 14)$ \\
\hline Quantity limits & $14(2 / 14)$ \\
\hline Open Access & $14(2 / 14)$ \\
\hline Yes & $50(7 / 14)$ \\
\hline No & $36(5 / 14)$ \\
\hline Unknown/other & $14(2 / 14)$ \\
\hline Yes & $71(10 / 14)$ \\
\hline Yes, if required by the REMS program & $21(3 / 14)$ \\
\hline No & $7(1 / 14)$ \\
\hline
\end{tabular}

Survey 2 Results (selected questions)

[Section] Statement

[platform therapies]

2.5 Patients with MS should not be required to try more than one IFN prior to trying another agent (i.e., glatiramer acetate, natalizumab).

[platform therapies]

2.6 Copaxone should be a preferred agent on a health plan's formulary.

[fingolimod]

4.7 Access to combination therapy with fingolimod and an injectable disease-

modifying therapy should be restricted until efficacy data are available.

Live Meeting Results (selected questions)

[platform therapies]

2.2 Health plans should have a preferred high dose/high

frequency IFN on formulary. ${ }^{\text {b }}$

[platform therapies]

2.7 Access to nonpreferred IFNs should be restricted by

step therapy or use of a preferred agent first.

[platform therapies]

2.8 Patients with MS should not be required to try more than one IFN

prior to trying another agent (i.e., glatiramer acetate, natalizumab).

[natalizumab]

3.3 Formulary restrictions should be in place to help manage

the safety concerns associated with natalizumab.

[natalizumab]

3.5 Safety data should be considered when reviewing

natalizumab for formulary placement.

[fingolimod]

4.1 Step therapy should be utilized by a health plan

to manage patient access to fingolimod.

\begin{tabular}{|l|c|c}
\multicolumn{1}{|c|}{ Response } & Response $\%$ & Mean Response \\
\hline 4-Strongly Agree & 14 & \multirow{2}{*}{2.9} \\
\hline 3-Agree & 64 & \\
\hline 2-Disagree & 23 & \multirow{2}{*}{3} \\
\hline 1-Strongly Disagree & 0 & \\
4-Strongly Agree & 36 & \\
\hline 3-Agree & 57 & \\
\hline 2-Disagree & 7 & \\
\hline 1-Strongly Disagree & 0 & \multirow{2}{*}{3.4} \\
4-Strongly Agree & 50 & \\
\hline 3-Agree & 43 & \\
\hline 2-Disagree & 7 & \\
\hline 1-Strongly Disagree & 0 &
\end{tabular}

\begin{tabular}{|c|c|c|}
\hline 4-Strongly Agree & 43 & \multirow{4}{*}{3.4} \\
\hline 3-Agree & 50 & \\
\hline 2-Disagree & 7 & \\
\hline 1-Strongly Disagree & 0 & \\
\hline 4-Strongly Agree & 43 & \multirow{4}{*}{3.4} \\
\hline 3-Agree & 57 & \\
\hline 2-Disagree & 0 & \\
\hline 1-Strongly Disagree & 0 & \\
\hline 4-Strongly Agree & 36 & \multirow{4}{*}{3.0} \\
\hline 3-Agree & 29 & \\
\hline 2-Disagree & 36 & \\
\hline 1-Strongly Disagree & 0 & \\
\hline 4-Strongly Agree & 14 & \multirow{4}{*}{2.7} \\
\hline 3-Agree & 50 & \\
\hline 2-Disagree & 29 & \\
\hline 1-Strongly Disagree & 7 & \\
\hline 4-Strongly Agree & 71 & \multirow{4}{*}{3.7} \\
\hline 3-Agree & 29 & \\
\hline 2-Disagree & 0 & \\
\hline 1-Strongly Disagree & 0 & \\
\hline 4-Strongly Agree & 43 & \multirow{4}{*}{3.1} \\
\hline 3 -Agree & 29 & \\
\hline 2-Disagree & 29 & \\
\hline 1-Strongly Disagree & 0 & \\
\hline
\end{tabular}

aThe 3 phases of the consensus panel included 2 anonymous web-based surveys and 1 live meeting of panel members conducted in December 2010.

${ }^{b}$ Considered by the panelists in the context of the availability of 3 high-dose/high-frequency IFNs.

IFN=interferon; $M S=$ multiple sclerosis; REMS = Risk Evaluation and Mitigation Strategies 


\section{TABLE 3 Consensus Panel Statements}

\begin{tabular}{|c|c|}
\hline Topic & Recommendations \\
\hline $\begin{array}{l}\text { Initiating disease- } \\
\text { modifying therapy }\end{array}$ & $\begin{array}{l}\text { 1. The decision to start patients with CIS on disease-modifying therapy should be left up to the provider. } \\
\text { 2. Most patients with CDMS should be treated with a disease-modifying therapy. }\end{array}$ \\
\hline $\begin{array}{l}\text { Platform } \\
\text { therapies: IFN } \\
\beta \text {-la IM; IFN } \beta \text {-lb } \\
\text { SC; IFN } \beta \text {-la SC; } \\
\text { glatiramer acetate }\end{array}$ & $\begin{array}{l}\text { 3. Both glatiramer acetate and a preferred IFN should be on a health plan's formulary. } \\
\text { 4. Patients with MS should have preferred access to platform therapies, including glatiramer acetate and at least one IFN. } \\
\text { 5. Glatiramer acetate should be a preferred agent on a health plan's formulary. } \\
\text { 6. Access to nonpreferred IFNs should be restricted by step therapy or use of a preferred agent first. } \\
\text { 7. Health plans should have a preferred high-dose/high-frequency IFN on formulary.a } \\
\text { 8. Health plans should take efficacy, safety, cost, and contracting into consideration when selecting the preferred high-dose/high- } \\
\text { frequency IFN for formulary. }\end{array}$ \\
\hline Natalizumab & $\begin{array}{l}\text { 9. Health plans should manage patient access to natalizumab with a PA or by requiring patients to fail an IFN or glatiramer acetate } \\
\text { first. } \\
\text { 10. Formulary restrictions should be in place to limit natalizumab use to the FDA-approved indication. } \\
\text { 11. Formulary restrictions should be in place to limit natalizumab use/reimbursement to once every } 28 \text { days. } \\
\text { 12. Step therapy should be in place to help manage the safety concerns associated with natalizumab. } \\
\text { 13. The TOUCH Prescribing Program should not be utilized in place of a PA. } \\
\text { 14. Safety is a factor in the use of a PA for natalizumab. } \\
\text { 15. Clinical efficacy, safety, and cost data should be considered when reviewing natalizumab for formulary placement. }\end{array}$ \\
\hline Fingolimod & $\begin{array}{l}\text { 16. PAs should be utilized by health plans to manage patient access to fingolimod. } \\
\text { 17. Formulary restrictions should be put in place to limit the use of fingolimod to neurologists. } \\
\text { 18. Access to combination therapy with fingolimod and an injectable disease-modifying therapy should be restricted until safety and } \\
\text { efficacy data are available. }\end{array}$ \\
\hline Dalfampridine & $\begin{array}{l}\text { 19. Dalfampridine is a symptom-management agent. } \\
\text { 20. Patient access to dalfampridine should be managed by a PA according to the FDA-approved labeled indication. } \\
\text { 21. Dalfampridine should be limited to patients who are also receiving a disease-modifying therapy. } \\
\text { 22. Efficacy, safety, and cost should be taken into consideration when reviewing dalfampridine for formulary placement. }\end{array}$ \\
\hline $\begin{array}{l}\text { Patient } \\
\text { considerations }\end{array}$ & $\begin{array}{l}\text { 23. Compliance and persistence to MS therapies is very important. } \\
\text { 24. MS patients need educational support/assistance. } \\
\text { 25. Some MS patients need financial support/assistance. }\end{array}$ \\
\hline
\end{tabular}

consensus that natalizumab's reimbursement should be limited to once every 28 days. The panelists indicated during their discussion that these restrictions are intended to manage the safety concerns associated with natalizumab. The panel did reach consensus that the TOUCH Prescribing Program should not be utilized in place of a prior authorization (PA). Utilization management tools discussed and recommended by the panel for natalizumab included a PA, requiring failure or intolerance of a prior therapy, and step therapy. The PA criteria for use of natalizumab for Crohn's Disease and coordination of the PA process for the 2 indications were not discussed. Most panelists (the specific number was not recorded) agreed during their discussion that the definition of MS treatment failure or intolerance should be left to the health care provider.

Consistent with the package insert, the panel acknowledged with consensus that the risk of PML is increased in patients who have been treated with an immunosuppressant prior to receiving natalizumab. The panel, however, did not make recommendations on the health plan's role in managing this risk, and some panelists (the specific number was not captured) stated during their discussion that the decision of when to use immunosuppressants in relation to natalizumab should be left to the health care provider. The panel did not achieve consensus on whether natalizumab should be used as first-line therapy in patients with highly active disease, as several (the specific number was not recorded) panelists stated during the discussion that this decision should be left to the health care provider. Several panel members (the specific number was not recorded) stated that patients should have significant input in the decision to use natalizumab and should understand the benefit-risk profile.

Through consensus, the panel recommended that PAs should be utilized by health plans to manage patient access to fingolimod. However, the panel did discuss that some health plans do not commonly use PAs for oral medications, even if the costs of the oral agents are very high. The panelists had varying opinions regarding the specific criteria for the PA; several (the specific number was not recorded) stated that the multiple monitoring requirements, cost, and unknown safety profile associated with fingolimod were reasons for managing patient access with a PA. The panel reached consensus that formulary restrictions should be put in place to limit the use of fingolimod to neurologists. However, since some patients may not have access to a neurologist due to geographic 
challenges, the panel discussed that this restriction should apply only to the initial treatment. Fingolimod had been available for only a short time (approximately 3 months) at the time of the panel meeting, and some panelists (the specific number was not recorded) stated that more safety data were needed. The panel's discussion on fingolimod did not include consideration of step-therapy criteria.

Due to limitations in data on combination therapy at the time of this panel meeting, the panel reached consensus that health plans should restrict access to combination therapy with fingolimod and injectable disease-modifying therapy until further efficacy and safety data become available. Consensus was not achieved on whether multiple monitoring requirements, or the cost of these monitoring requirements, should affect a health plan's formulary decision for fingolimod.

The panel reached consensus that patient access to dalfampridine should be managed by a PA according to the FDA-approved labeled indication. Again, the panel discussed that some health plans do not commonly use PAs for oral medications, even though the costs of some of these agents are very high. The panelists had varying opinions regarding the specific criteria for the PA. The panel agreed through consensus that dalfampridine should be limited to patients who are also receiving a disease-modifying therapy. The panel reached consensus that efficacy, safety, and cost should be considered when reviewing dalfampridine for formulary placement. The panel discussed that safety is most relevant when evaluating a symptom-management agent.

\section{Patient Considerations}

The panel addressed several patient considerations. Patient compliance and persistence to MS therapies were highlighted as very important. However, during the discussion, panelists noted a paucity of data demonstrating the impact of compliance on outcomes in MS and stated that these data would be needed in order to utilize compliance data in formulary decisions. Consensus was not reached on whether compliance and persistence data should be considered when making formulary decisions, as panelists discussed that they would need to see that data in order to make that determination. It was also noted during the panelists' discussion that due to the episodic nature of MS, gaps in persistency may be acceptable for some patients.

The panel reached consensus that patients with MS may need educational and financial support. Educational support was discussed as a shared responsibility among many stakeholders, including the MS societies, physicians' offices, specialty pharmacies, pharmaceutical manufacturers, and health plans. The panel discussed that services provided by the listed stakeholders should not be duplicative. Panelists did not determine who should provide financial support or how it should be provided, but it was recognized that financial support is needed for some patients with MS. Consensus was not achieved regarding whether patients should be required to enroll in a patient support program.

\section{Discussion}

MS is a chronic and debilitating disease, and the goal of currently available therapies is to prevent relapses and delay disability progression. ${ }^{12}$ The significant economic burden of MS to third-party payers has put pressure on payers to effectively manage the cost while maintaining clinical outcomes. Treatment guidelines exist for MS; however, variations exist across the available guidelines regarding the recommendations for the management of the agents used to treat MS. The NICE guidelines, issued in 2003, provide a wealth of useful information that includes health economic analyses, 189 specific recommendations that address management of 19 MS symptoms, and incorporate evidence from patient-reported outcomes as well as physician-reported outcomes. ${ }^{1}$ The NICE guidelines recommend that MS patients be referred to neurology specialists for proper diagnosis and monitoring of diseasemodifying treatment. ${ }^{27}$ Even though the 2003 NICE guidelines do not address fingolimod and the preliminary NICE guidance published in August 2011 recommends that fingolimod not be used for the treatment of RRMS, the NICE guidelines for treatment of MS are consistent with the consensus statement of this Delphi panel, which suggested that formulary restrictions should be put in place to limit the use of fingolimod to neurologists. ${ }^{27}$ However, the NICE guidelines are not necessarily applicable to the U.S. market. Therefore, U.S. health plans need a current framework to support formulary placement and clinical management strategies for MS therapies.

\section{Limitations}

Foremost among the limitations of the recommendations developed from this modified Delphi process was the absence of clinical practice experience in treating MS among panel participants. This may explain why 3 panel participants (21\%) in the first web-based survey indicated that they did not understand what platform therapies meant and therefore did not provide an answer to the question "How should a health plan manage patient access to platform therapies, if at all?" The recommendations that emerged from this modified Delphi process were developed by experts in managed care; therefore, their opinions reflect the perspective of designing and managing health benefits. Practicing neurologists and the specialists who treat patients with MS may have different opinions than pharmacy and medical directors of health plans.

Second, some of the panel participants were apparently unaware of the existence of MS treatment guidelines. In the first web-based survey, 57\% (8/14) of panel participants indicated that they were not aware of "evidence-based treatment 
guidelines for MS." In the second round of the web-based survey, 50\% (7/14) of panel participants agreed with the statement "I am not aware of any evidence-based treatment guidelines for MS," and in the live meeting, 29\% (4/14) of panel participants agreed with this statement.

Third, the findings may reflect inherent variability of the panelists with respect to their education, experience with the topic, and responsibility within their respective health plans. Fourth, the opinions and responses expressed by these panelists do not necessarily reflect the position of their respective health plans or the universe of health plans from which this small convenience sample was drawn. Health plans with primarily commercial, Medicare, or Medicaid populations may have differing opinions and options than those of the panelists.

Fifth, as described in the Methods section, this modified Delphi approach included 1 live meeting, which sacrificed the anonymity of the panel members. This format may have introduced bias based on the opinions of more vocal panelists. Sixth, fingolimod had been on the market for only a short time, less than 3 months at the time of the Delphi panel live meeting, and the findings should be interpreted in the context of limited experience.

Finally, this panel did not consider the cost of MS therapies. The MS treatment landscape will continue to evolve in the future due to the ever-changing market environment. The cost of MS therapies is a major concern for health plans and will continue to be a concern with the entrance of new MS therapies into the market. In the future, there is the potential for combination therapy and more individualization of therapies, which could also lead to increased costs. Cost and comparative effectiveness issues should be addressed as data continue to emerge, and future panels may also consider the value of (a) MRI data as they relate to the management of agents used for the treatment of MS, and (b) anti-JC Antibody Assay as a means to stratify MS patients considering or receiving natalizumab to assess their risk for developing PML. ${ }^{28}$

\section{Conclusion}

A need remains for a comprehensive, current U.S.-focused guideline for the treatment of MS. Until that time, payers are challenged to make management decisions in the MS category without clinical consensus. This challenge is compounded by new therapeutic agents in the category and mounting cost containment pressures. The consensus statements produced by this modified Delphi process involving managed care experts provide a reference for health plans in designing their benefits and coverage policies for MS agents and should be used in conjunction with clinical evidence. Future opportunity exists to seek commentary on this reference from neurology experts and to update the statements as new agents enter the market.

\section{Authors}

ROSS M. MILLER, MD, MPH, is Consulting Medical Executive, Cerner LifeSciences, Beverly Hills, California; LAURA E. HAPPE, PharmD, MPH, is Associate Professor of Pharmacy Administration, Presbyterian College School of Pharmacy, and Consultant, Xcenda, Palm Harbor, Florida. KELLIE L. MEYER, PharmD, MPH, is Director, Global Outcomes Solutions; and RACHEL J. SPEAR, PharmD, is Health Outcomes and Managed Markets Fellow, Xcenda, Palm Harbor, Florida.

AUTHOR CORRESPONDENCE: Kellie L. Meyer, PharmD, MPH, Director, Xcenda, 4114 Woodlands Pkwy., Ste. 500,

Palm Harbor, FL 34685. Tel. 617.650.3267; Fax: 727.771.4145;

E-mail: kellie.meyer@xcenda.com

\section{DISCLOSURES}

Financial support for this research was provided by Biogen Idec, manufacturer of natalizumab (Tysabri) and IFN $\beta$-la IM (Avonex). Miller was a paid consultant to Biogen Idec for the purposes of this project. Meyer, Happe, and Spear are employed by Xcenda, a consulting company that provides services to Biogen Idec and other pharmaceutical manufacturers.

Happe conceived and designed the project, with the assistance of Meyer and Miller. Meyer collected the data with the assistance of Happe and Miller The 4 authors interpreted the survey data and wrote the manuscript. Meyer and Spear revised the manuscript.

\section{ACKNOWLEDGEMENTS}

Gary Owens, MD (Glen Mills, PA), served as the moderator for the live consensus meeting. The following individuals agreed to be identified as participants in the Delphi panel process: Donald Balfour, MD, Sharp Rees-Stealy Medical Group (San Diego, CA); Jeff Dunn, PharmD, MBA, SelectHealth (Salt Lake City, UT); Robert Jaramillo, PharmD, RPh, Public Employees Health Program (Salt Lake City, UT); Gary L. Johnson, MD, MBA, Humana Inc. (Madison, WI); Raj Kabali, RPh, MBA, Capital BlueCross (New Cumberland, PA); Maria Lopes, MD, MS, AMC Health (Cresskill, NJ); Ross Miller, MD MPH, Department of Health Care Services (Los Angeles, CA); Gary Rice, RPh, MS, MBA, ITSRx (Humble, TX); Joe Sinopoli, RPh, PreLaunch Strategy (North Reading, MA). The remaining 5 panelists chose not to be identified by name; their positions were as follows: 2 national managed care organization (MCO) medical directors and $3 \mathrm{MCO}$ pharmacy directors (1 national, 1 from the Northeast, and 1 from the Midwest)

\section{REFERENCES}

1. Trisolini MG. Comparison of multiple sclerosis guidelines underscores need for collaboration. Agency for Healthcare Research and Quality. December 8, 2008. Available at: http://www.guideline.gov/expert/expertcommentary.aspx?id=16443. Accessed November 13, 2011.

2. National Multiple Sclerosis Society. Available at: http://www.nationalmssociety.org/index.aspx. Accessed November 13, 2011

3. Bainbridge JL, Corboy JR. Multiple sclerosis. In: Dipiro JT, Talbert RL, Yee GC, Matzke GR, Wells BG, Posey LM, eds. Pharmacotherapy: A Pathophysiologic Approach. 7th ed. New York, NY: McGraw-Hill; 2008:913-26.

4. Miller D, Barkhof F, Montalban X, Thompson A, Filippi M. Clinically isolated syndromes suggestive of multiple sclerosis, part 1 : natural history, pathogenesis, diagnosis, and prognosis. Lancet Neurol. 2005;4(5):281-88.

5. Wingerchuk DM. Current evidence and therapeutic strategies for multiple sclerosis. Semin Neurol. 2008;28(1):56-68. 
6. Brex PA, Ciccarelli O, O’Riordan JI, Sailer M, Thompson AJ, Miller DH. A longitudinal study of abnormalities on MRI and disability from multiple sclerosis. N Engl J Med. 2002;346(3):158-64. Available at: http://www.nejm. org/doi/full/10.1056/NEJMoa011341. Accessed November 13, 2011.

7. Leary SM, Porter B, Thompson AJ. Multiple sclerosis: diagnosis and the management of acute relapses. Postgrad Med J. 2005;81(955):30208. Available at: http://pmj.bmj.com/content/81/955/302.long. Accessed November 13, 2011.

8. Alonso-Magdelena L, Romero-Pinel L, Moral E, et al. Anticipation of age at onset in multiple sclerosis: methodologic pitfalls. Acta Neurol Scand. 2010;121(6):426-28.

9. U.S. Census Bureau, Current Population Survey, 2010 Annual Social and Economic Supplement. Available at: http://www.census.gov/hhes/www/ cpstables/032010/health/h05_000.htm. Accessed November 13, 2011.

10. Asche CV, Singer ME, Jhaveri M, Chung H, Miller A. All-cause health care utilization and costs associated with newly diagnosed multiple sclerosis in the United States. J Manag Care Pharm. 2010;16(9):703-12. Available at: http://www.amcp.org/data/jmcp/703-712.pdf.

11. Schafer JA, Gunderson BW, Gleason PP. Price increases and new drugs drive increased expenditures for multiple sclerosis. J Manag Care Pharm. 2010;16(9):713-17. Available at: http://www.amcp.org/data/jmcp/713-717. pdf.

12. Goodin DS, Frohman EM, Garmany GP, et al. Disease modifying therapies in multiple sclerosis: report of the Therapeutics and Technology Assessment Subcommittee of the American Academy of Neurology and the MS Council for Clinical Practice Guidelines. Neurology. 2002;58(2):169-78. Available at: http://www.aan.com/professionals/practice/pdfs/gl0091.pdf. Accessed November 13, 2011.

13. Coleman IC, Cook R, Gade JN, et al. Meeting the challenge of incorporating injectable biologics into managed care: multiple sclerosis and psoriasis. J Manag Care Pharm. 2004;10(3)(Suppl S-b):S1-S45. Available at: http:// www.amcp.org/data/jmcp/June04Supplementl.pdf.

14. Copaxone (glatiramer acetate injection) solution for subcutaneous injection. Teva Neuroscience, Inc. February 2009. Available at: http://www. sharedsolutions.com/pdfs/PrescribingInformation.aspx. Accessed November 13, 2011.

15. Extavia (interferon beta-lb) for subcutaneous injection. Novartis Pharmaceuticals Corporation. August 2009. Available at: http://www. pharma.us.novartis.com/product/pi/pdf/extavia.pdf. Accessed November 13, 2011.
16. Betaseron (interferon beta-1b) for subcutaneous injection. Bayer HealthCare Pharmaceuticals. May 2010. Available at: http://berlex.bayerhealthcare.com/html/products/pi/Betaseron_PI.pdf. Accessed November 13, 2011.

17. Avonex (interferon beta-la) for IM injection. Biogen Idec Inc. June 2011. Available at: http://www.avonex.com/pdfs/pi-syringe.pdf. Accessed November 13, 2011.

18. Rebif (interferon beta-la) for subcutaneous injection. EMD Serono, Inc. September 2009. Available at: http://media.pfizer.com/files/products/uspi_ rebif.pdf. Accessed November 13, 2011.

19. Tysabri (natalizumab) injection for intravenous use. Biogen Idec Inc. September 2011. Available at: http://www.tysabri.com/en_US/tysb/site/pdfs/ TYSABRI-pi.pdf. Accessed November 13, 2011.

20. Gilenya (fingolimod) capsules. Novartis Pharmaceuticals Corporation. July 2011. Available at: http://www.pharma.us.novartis.com/product/pi/pdf/ gilenya.pdf. Accessed November 13, 2011.

21. Ampyra (dalfampridine) extended release tablets. Acorda Therapeutics, Inc. January 2010. Available at: http://ampyra-hcp.com/local/files/PI.pdf. Accessed November 13, 2011.

22. McKenna H. The Delphi technique: a worthwhile approach for nursing? J Adv Nurs. 1994;19(6):1221-25.

23. Hasson F, Keeney S, McKenna HP. Research guidelines for the Delphi survey technique. J Adv Nurs. 2000;32(4):1008-15.

24. Keeney S, Hasson F, McKenna H. A critical review of the Delphi technique as a research methodology for nursing. Int J Nurs Stud. 2001;38(2):195200.

25. Brook R, Chassin M, Fink A, Solomon DH, Kosecoff J, Park RE. A method for the detailed assessment of the appropriateness of medical technologies. Int J Technol Assess Health Care. 1986;2(1):53-63.

26. Wyrich KW, Spertus JA, Kroenke K, Tierney WM, Babu AN, Wolinsky FD. Clinically important differences in health status for patients with heart disease: an expert consensus panel report. Am Heart J. 2004;147(4):615-22.

27. National Institute for Clinical Excellence. Multiple sclerosis (relapsingremitting) - fingolimod. September 7, 2011. Available at: http://guidance. nice.org.uk/TA/Wave20/71. Accessed November 13, 2011.

28. Gorelik L, Lerner M, Bixler S, et al. Anti-JC virus antibodies: implications for PML risk stratification. Ann Neurol. 2010;68(3):295-303. 